\title{
Perancangan dan Pengukuran Kinerja Supply Chain dengan Menggunakan Metode SCOR
}

\section{Erixson Rumahorbo ${ }^{1^{*}}$, Wahyuda ${ }^{2}$, Anggriani Profita ${ }^{3}$}

Program Studi Teknik Industri, Fakultas Teknik, Universitas Mulawarman

Jl. Sambaliung No.9, Kampus Gunung Kelua, Samarinda 75119, Kalimantan Timur, Indonesia erixsonrumahorbo08@gmail.com ${ }^{1 *}$,wahyuda@ft.unmul.ac.id ${ }^{2}$, profita@ ft.unmul.ac.id ${ }^{3}$

\begin{tabular}{l} 
INFO ARTIKEL \\
\hline Jejak Artikel : \\
Upload artikel \\
O5 Februari 2020 \\
Revisi \\
O1 Agustus 2021 \\
Publish \\
30 September 2021
\end{tabular}

Kata Kunci :

Supply Chain, KPI, SCOR,

AHP, Snorm De Boer, Traffic

Light System
ABSTRAK

Pabrik Penggilingan Padi UD Sido Muncul merupakan salah satu industri bahan pangan beras siap konsumsi yang proses penggilingan padinya tidak terlepas dari kinerja supply chain. Kinerja supply chain harus dioptimalkan agar meningkatkan daya saing pabrik dengan pabrik penggilingan padi lainnya sekaligus menaikkan pendapatan pabrik. Oleh sebab itu perlu dilakukan perancangan Key Performance Indikator (KPI) pabrik kemudian dilakukan pengukuran kinerja supply chain-nya. Perancangan dilakukan dengan menggunakan metode SCOR versi 10.0 sesuai 5 proses utama yaitu plan, source, make, deliver, dan return, untuk pengukuran dilakukan pembobotan terlebih dahulu terhadap setiap kriteria, variabel, dan KPI menggunakan AHP, setelah itu dilakukan uji konsistensi, pembobotan global, lalu menyamakan parameter nilai aktual setiap KPI dengan normalisasi Snorm De Boer, mengidentifikasi kinerja yang tergolong sangat baik, cukup, dan buruk dengan Traffic Light System (TLS), kemudian dilakukan pengukuran nilai akhir kinerja supply chain dengan mengalikan bobot global dengan nilai Snorm masing-masing KPI. Hasil dari perancangan didapatkan 27 KPI dengan 13 variabel. Berdasarkan rancangan tersebut dilakukan pengukuran kinerja supply chain sehingga didapatkan 12 KPI tergolong sangat baik, 11 KPI tergolong cukup, 4 KPI tergolong buruk dan kinerja sebesar 72,839 yang tergolong ke dalam Good Performance. Untuk mengoptimalkan kinerja dan meningkatkan pendapatan, perlu dilakukan perbaikan terhadap 4 kinerja buruk tersebut. 


\section{Pendahuluan}

Penggilingan padi merupakan bagian dari rantai pasok beras dan memiliki kontribusi penting dalam penyediaan beras dari segi kuantitas dan kualitas untuk mendukung ketahanan pangan nasional. Penggilingan padi berperan penting dalam menyediakan beras untuk memenuhi kebutuhan pangan masyarakat, menjadi titik sentral pengolahan atau perubahan bentuk padi menjadi beras, menentukan kuantitas dan kualitas beras, menentukan tingkat harga gabah dan beras, serta membuka peluang lapangan pekerjaan [1].

Berdasarkan hasil Pendataan Industri Penggilingan Padi (PIPA) yang dilakukan oleh BPS pada tahun 2012, jumlah penggilingan yang ada di Indonesia sebanyak 182.198 unit. Penggilingan tersebut terdiri dari 169.043 unit $(92,78 \%)$ kapasitas kecil, 8.628 unit $(4,74 \%)$ kapasitas sedang, 2.075 unit $(1,14 \%)$ kapasitas besar, dan 2.452 unit $(1,35 \%)$ tidak tercatat golongan kapasitasnya (Badan Ketahanan Pangan, 2018). Kalimantan Timur merupakan salah satu provinsi yang ada di Indonesia. Beberapa daerah di Kalimantan Timur sudah memiliki penggilingan padi sendiri. Salah satunya adalah Kecamatan Babulu yang berada di Kabupaten Penajam Paser Utara (PPU). Berdasarkan data terakhir yang diperoleh oleh BPS pada Direktori Perusahaan Industri Penggilingan Padi (PIPA) Kalimatan Timur tahun 2012, terdapat 73 penggilingan padi yang berstatus tetap. Akan tetapi masih banyak penggilingan padi yang belum memaksimalkan usahanya sehingga hasil panen padi di daerah tersebut masih dikuasai oleh para tengkulak yang berasal dari luar Kabupaten PPU (Badan Pusat Statistik, 2012 dalam Badan Ketahanan Pangan, 2018).

Kecamatan Babulu Kabupaten PPU merupakan sentra pertanian padi di kabupaten tersebut. Lahan pertanian padi yang luas menjadikan kabupaten tersebut sebagai salah satu lumbung pangan di Kalimantan Timur. Namun sejumlah masyarakat petani padi di Kecamatan Babulu masih mengeluhkan kondisi pertanian mereka selama ini. Bahkan menurut sejumlah petani di wilayah tersebut, penjualan hasil panen di Kecamatan Babulu masih dikuasai oleh tengkulak asal luar daerah yang pada umumnya berasal dari Kalimantan Selatan. Tengkulak tersebut membeli gabah hasil pertanian dari petani padi Kecamatan Babulu dengan harga murah. Harga yang diberikan oleh para tengkulak berkisar $\mathrm{Rp}$ 4000 per kilogram gabah (Penajamkab, 2019). Pabrik penggilingan padi yang berada di Kecamatan Babulu masih memberikan harga yang cukup bersaing. Ketika musin panen, pabrik penggilingan padi yang berada di wilayah tersebut akan memberikan harga yang sama dengan para tengkulak yang berasal dari Kalimantan Selatan. Ketika musim kemarau, pabrik penggilingan padi yang berada di wilayah Kecamatan Babulu berani memberikan harga Rp 5000 sampai dengan Rp 5.500 per kilogram gabah sedangkan para tengkulak dari Kalimantan Selatan masih mematok harga yang sama. Berdasarkan hal tersebut, para petani padi di Kecamatan Babulu harus benar-benar memanfaatkan penggilingan padi yang sudah ada di daerah tersebut untuk mengolah padi mereka menjadi beras.

Pabrik Penggilingan Padi UD Sido Muncul merupakan salah satu industri bahan pangan beras siap konsumsi yang terdapat di desa Labangka, Kecamatan Babulu, Kabupaten PPU. Pabrik penggilingan padi UD Sido Muncul berdiri sejak tahun 2012 dengan ratarata produksi berasnya mencapai 700 ton setiap tahun. Pada proses produksinya, pabrik penggilingan padi UD Sido Muncul mendapatkan bahan baku gabah dari para petani yang bertani di kawasan Kecamatan Babulu dan sekitarnya. Bahan baku gabah diproses menggunakan mesin di pabrik penggilingan padi hingga menjadi beras kemudian dipasarkan secara langsung kepada konsumen yang datang ke pabrik penggilingan padi UD Sido Muncul. Selain itu, pabrik penggilingan padi UD Sido Muncul juga memasarkan beras hasil produksinya kepada agen-agen beras yang berada di berbagai wilayah Kabupaten PPU seperti Penajam, Tanah Grogot dan Long Kali serta yang berada di luar wilayah Kabupaten PPU seperti Kota Balikpapan.

Melihat cakupan pabrik penggilingan padi UD Sido Muncul yang sudah menguasai pasar Kabupaten PPU hingga Kota Balikpapan, maka diperlukan perancangan Key Performance Indicator (KPI) supply chain pabrik dan pengukuran kinerjanya. Diharapkan dengan menggunakan model SCOR, dapat diketahui KPI supply chain yang sesuai untuk 
pabrik, nilai kinerja pabrik, serta dapat diketahui juga KPI yang memerlukan perbaikan oleh pabrik penggilingan padi UD Sido Muncul sehingga dapat meningkatkan kinerja supply chain pabrik[2][3].

\section{Metode Penelitian}

\section{Supply Chain Management (SCM)}

SCM merupakan gabungan dari proses bisnis yang saling keterkaitan antara aspek internal maupun eksternal perusahaan yang dimulai dari penyuplai hingga ke konsumen. Proses bisnis yang terlibat meliputi pemasok, pabrik, gudang, pengangkut, distributor, retailer, dan konsumen. Seluruh proses bisnis tersebut diintegarasi dan bekerja secara efisien untuk menghasilkan produk yang sesuai dengan target yang diinginkan, seperti ketepatan jumlah produksi, kualitas yang baik, serta waktu dan lokasi yang sesuai. SCM merupakan pengembangan dari manajemen logistik. SCM dan manajemen logistik samasama melaksanakan kegiatan aliran barang termasuk pembelian, pengendalian persediaan, pengangkutan, penyimpanan, dan distribusi. Kekurangan dari manajemen logistik adalah kegiatan yang dilakukan terbatas dalam satu perusahaan saja, sedangkan SCM meliputi antar perusahaan mulai dari bahan hingga barang yang siap pakai oleh konsumen [4][5].

\section{Sistem Pengukuran Kinerja Supply Chain}

Salah satu aspek fundamental dalam SCM adalah manajemen kinerja dan perbaikan secara berkelanjutan. Untuk menciptakan manajemen kinerja yang efektif diperlukan sistem pengukuran yang mampu mengevaluasi kinerja supply chain secara holistik. Menciptakan sistem pengukuran kinerja supply chain bukanlah pekerjaan yang mudah. Menentukan apa yang akan diukur dan dimonitor untuk menciptakan kesesuaian antara strategi supply chain dengan metrik pengukuran, setiap berapa periode pengukuran dilakukan, dan seberapa penting ukuran yang satu relatif terhadap yang lain [6][7].

\section{Tujuan Pengukuran Kinerja Supply Chain}

Menurut [8] terdapat beberapa tujuan pengukuran kinerja supply chain yaitu sebagai berikut:

1. Melakukan monitoring dan pengendalian
2. Mengkomunikasikan tujuan organisasi ke fungsi-fungsi pada supply chain

3. Mengetahui dimana posisi suatu organisasi relatif terhadap pesaing maupun terhadap tujuan hendak dicapai

4. Menentukan arah perbaikan untuk menciptakan keunggulan dalam bersaing.

\section{Supply Chain Operation Reference (SCOR)}

SCOR membagi proses-proses supply chain menjadi 5 proses inti, yaitu plan, source, make, deliver, dan return[9][10]. Uraiannya adalah sebagai berikut:

1. Plan

Yaitu proses yang menyeimbangkan permintaan dan pasokan untuk menentukan tindakan terbaik dalam memenuhi kebutuhan pengadaan, produksi, dan pengiriman. Plan mencakup proses menaksir kebutuhan distribusi, perencanaan dan pengendalian persediaan, perencanaan produksi, perencanaan material, perencanaan kapasitas, dan melakukan penyesuaian supply chain plan dengan financial plan.

2. Source

Yaitu proses pengadaan barang maupun jasa untuk memenuhi permintaan. Proses yang dicakup termasuk penjadwalan pengiriman dari supplier, menerima, mengecek, dan memberikan otorisasi pembayaran untuk barang yang dikirim supplier, memilih supplier, mengevaluasi kinerja supplier, dan sebagainya. Jenis proses bisa berbeda tergantung pada apakah barang yang dibeli termasuk stocked, maketo-order, atau engineer-to-order products.

3. Make

Yaitu proses untuk mentransformasikan bahan baku/komponen menjadi produk yang diinginkan pelanggan. Kegiatan make atau produksi bisa dilakukan atas dasar ramalan untuk memenuhi target stok, atas dasar pesanan, atau engineer-to-order. Proses yang terlibat di sini antara lain adalah penjadwalan produksi, melakukan kegiatan produksi dan melakukan pengetesan kualitas, mengelola barang setengah jadi (work-in-process), memelihara fasilitas produksi, dan sebagainya.

4. Deliver 
Merupakan proses untuk memenuhi permintaan terhadap barang maupun jasa. Biasanya meliputi order management, transportasi, dan distribusi. Proses yang terlibat diantaranya adalah menangani pesanan dari pelanggan, memilih perusahaan jasa pengiriman, menangani kegiatan pergudangan produk jadi, dan mengirim tagihan ke pelanggan.

\section{Return}

Yaitu proses pengembalian atau menerima pengembalian produk karena berbagai alasan. Kegiatan yang terlibat antara lain identifikasi kondisi produk, meminta otorisasi pengembalian cacat, penjadwalan pengembalian, dan melakukan pengembalian. Post-delivery customer support juga merupakan bagian dari proses return.

SCOR memiliki tiga hirarki proses. Tiga hirarki tersebut menunjukkan bahwa SCOR melakukan dekomposisi proses dari yang umum ke yang detail seperti halnya model Chan \& Li [11][12]. Berikut ini merupakan tiga level tersebut, yaitu:

1. Level 1 adalah level tertinggi yang memberikan defenisi umum dari lima proses (plan, source, make, deliver, dan return).

2. Level 2 dikatakan sebagai configuration level dimana supply chain perusahaan bisa membentuk konfigurasi berdasarkan 30 proses inti. Perusahaan bisa membentuk konfigurasi saat ini maupun yang diinginkan.

3. Level 3 dinamakan process element level, mengandung defenisi elemen proses, input, output, metrik masing-masing elemen proses serta referensi (benchmark dan best practice).

\section{Analytical Hierarchi Process (AHP)}

Model AHP diperkenalkan pertama kali oleh Thomas L. Saaty pada era 1970-an. Model yang berada di wilayah probabilistik ini merupakan model pengambilan keputusan dan perencanaan strategis[13]. Ciri khas dari model ini adalah penentuan skala prioritas atas alternatif pilihan berdasarkan suatu proses analitis secara berjenjang, terstruktur atas variabel keputusan. Ide dasar dari model ini memiliki kemiripan dengan konsep taksonomi dalam disiplin ilmu biologi. Taksonomi pada intinya merupakan pemodelan secara bertingkat atas organisme: kingdom, class, orde, genera, dan species. Dalam model ini, proses analisis terhadap suatu masalah dilakukan secara berjenjang dan terstruktur. Adapaun bangun dasar konsep matematis yang dipakai adalah matriks. Karenanya, pemahaman yang cukup baik tentang konsep matriks akan membantu dalam memahami sejumlah konsep dasar dan penggunaan dari model kuantitatif ini [14].

Tabel 1. Skala penilaian perbandingan berpasangan

\begin{tabular}{|c|c|}
\hline $\begin{array}{c}\text { Tingkat } \\
\text { Kepentingan }\end{array}$ & Defenisi \\
\hline 1 & Kedua elemen sama penting \\
\hline 3 & $\begin{array}{l}\text { Elemen yang satu sedikit lebih } \\
\text { penting dibanding elemen } \\
\text { lainnya }\end{array}$ \\
\hline 5 & $\begin{array}{l}\text { Elemen yang satu sangat } \\
\text { penting dibanding elemen } \\
\text { yang lainnya }\end{array}$ \\
\hline 7 & $\begin{array}{l}\text { Elemen yang satu benar-benar } \\
\text { lebih penting dari lainnya }\end{array}$ \\
\hline 9 & $\begin{array}{l}\text { Elemen yang satu mutlak } \\
\text { lebih penting dibanding } \\
\text { elemen yang lainnya }\end{array}$ \\
\hline $2,4,6,8$ & $\begin{array}{l}\text { Nilai tengah diantara dua } \\
\text { penilaian berurutan }\end{array}$ \\
\hline
\end{tabular}

\section{Normalisasi Snorm De Boer}

Normalisasi memegang peranan cukup penting demi tercapainya nilai akhir dari pengukuran kinerja, setiap indikator memiliki bobot yang berbeda-beda dengan skala ukuran yang berbeda-beda pula [15][16]. Proses normalisasi dilakukan dengan rumus normalisasi Snorm De Boer, dengan persamaan berikut:

\section{Larger is Better}

$$
\text { Snorm }=\frac{(\text { SI - Smin })}{\text { Smax }- \text { Smin }} \times 100
$$

2. Smaller is Better

$$
\text { Snorm }=\frac{(\text { Smax }- \text { SI) }}{\operatorname{Smax}-\mathrm{Smin}} \times 100
$$

indikator kinerja dibagi menjadi lima kondisi yang dapat dilihat pada Tabel 2. 
Tabel 2. Kondisi indikator kinerja

\begin{tabular}{|c|c|}
\hline $\begin{array}{c}\text { Nilai Indikator } \\
\text { Kinerja }\end{array}$ & $\begin{array}{c}\text { Kondisi Indikator } \\
\text { Kinerja }\end{array}$ \\
\hline $0-40$ & Poor Performance \\
\hline $40-50$ & Marginal Performance \\
\hline $50-70$ & Average Performance \\
\hline $70-90$ & Good Performance \\
\hline $90-100$ & Excellent Performance \\
\hline
\end{tabular}

Sumber: Vollby (2000) dalam Ardhanaputra (2019)

\section{Traffic Light System (TLS)}

Traffic Light System adalah suatu metode yang digunakan untuk mempermudah dalam memahami pencapaian kinerja perusahaan dengan bantuan 3 kategori warna yaitu merah, kuning, dan hijau. Batas dari masing-masing kategori warna tersebut ditetapkan melalui hasil diskusi dengan pihak perusahaan. Kategori warna tersebut dapat mempermudah pihak perusahaan untuk mengevaluasi kinerja perusahaan yang sesuai dengan target maupun yang tidak mencapai [17[18]

terdapat kategori nilai untuk batas 3 warna pada traffic light system [19][20][21][22], yaitu sebagai berikut:

1. Warna merah menandakan bahwa skor/level berada di ambang batas 0 hingga 3 atau dalam skala 100 berarti 0 hingga 30 .

Kategori ini tergolong pada penilaian performa kurang baik, yang realisasinya berada di bawah target yang telah ditetapkan oleh perusahaan.

2. Warna kuning menandakan bahwa skor/level berada di ambang batas 4 hingga 7 atau dalam skala 100 berarti 40 hingga 70 yang berarti kinerja perusahaan tergolong pada penilaian performa yang cukup atau yang realisasinya belum mencapai target maksimum.

3. Warna hijau menandakan bahwa skor/level berada di ambang batas 8 hingga 10 atau dalam skala 100 berarti 80 hingga 100 yang berarti kinerja perusahaan telah mencapai performa yang diharapkan. Golongan yang berwarna hijau ini sangat baik, karena telah mencapai target maksimum yang telah ditetapkan oleh perusahaan.

\section{Tempat dan Lokasi Penelitian}

Penelitin ini dilaksanakan pada Pabrik Penggilingan Padi UD Sido Muncul yang terletak di desa Labangka, Kecamatan Babulu, Penajam Paser Utara.

\section{Tahapan Penelitian}

Tahap penelitian terdiri dari beberapa tahap diantaranya adalah tahap persiapan, tahap pengumpulan data, tahap pengolahan data, tahap analisa, dan tahap penutup yang berisi kesimpulan dan saran.

Data yang diperlukan dalam penelitian ini yaitu data primer dan sekunder. Data primer didapatkan dari hasil observasi, wawancara, dan kuesioner. Data sekunder didapatkan dari pembukuan ataupun secara langsung dari pemilik pabrik dan dari media berupa arsip yang dipublikasikan maupun yang tidak dipublikasikan secara umum.

Berdasarkan data yang telah dikumpulkan, selanjutnya dilakukan pengolahan data. Pada tahap pengolahan data dibagi menjadi delapan bagian pengolahan data yaitu pengolahan data dengan metode SCOR, AHP, uji konsistensi, pembobotan global, pengolahan nilai aktual, Snorm De Boer, TLS, dan penentuan nilai akhir kinerja supply chain.

1. Pengolahan data dengan metode SCOR

Pengolahan data dengan metode SCOR dilakukan untuk mendapatkan rancangan KPI yang akan dijadikan sistem pengukuran kinerja supply chain pabrik penggilingan padi UD Sido Muncul. Rancangan dibuat berdasarkan hasil wawncara dengan pemilik pabrik sesuai dengan 5 proses utama KPI yaitu plan, source, make, deliver, dan return.

2. Pengolahan data dengan metode AHP Metode AHP digunakan untuk melakukan pembobotan terhadap KPI yang sudah dirancang. Adapun tahapannya adalah sebagai berikut:

a. Melakukan pembobotan dari hasil kuesioner perbandingan berpasangan terhadap setiap kriteria, variabel, dan KPI dan

b. Membuat normalisasi setiap hasil matriks dari hasil pengolahan kuesioner perbandingan berpasangan

3. Pengolahan data dengan uji konsistensi

Uji konsistensi dilakukan untuk membuktikan bahwa setiap pembobotan dan perbandingan yang dilakukan adalah konsisten. Pembobotan dikatakan konsisten apabila CI sama dengan nol dan CR $<0,1$.

4. Penentuan bobot global

Bobot global diperlukan sebagai bobot akhir yang akan dikalikan dengan hasil 
Snorm De Boer sehingga nantinya didapatkan nilai akhir kinerja supply chain. Bobot glogal didapatkan dengan cara mengalikan bobot kriteria dengan bobot variabel dan dengan bobot setiap KPI.

5. Pengolahan nilai aktual

Nilai aktual didapatkan dari hasil bagi antara pencapaian pabrik dengan target yang ditetapkan oleh pabrik. Pengukuran nilai aktual dilakukan pada bulan penelitian, pada bulan yang pencapaiannya terendah, dan pada bulan yang pencapaiannya tertinggi pada 1 tahun kerja.

6. Normalisasi Snorm De Boer

Normalisasi dilakukan agar nilai aktual yang didapatkan memiliki parameter yang sama untuk setiap KPInya sehingga dapat dilakukan analisis. Hasil Snorm ini juga akan menjadi penentu untuk metode TLS.

7. Pengolahan data dengan metode TLS

Pengolahan dengan metode TLS dilakukan untuk mengkategotikan setiap kinerja KPI apakah tergolong ke dalam kinerja sangat baik yang disimbolkan dengan warna hijau, kinerja cukup yang disimbolkan dengan warna kuning, dan kinerja buruk yang disimbolkan dengan warna merah. Setiap kategori memiliki range nilai yang berbeda sesuai dengan ketentuan dengan pemilik pabrik.

8. Penentuan nilai akhir kinerja supply chain

Tahap pengolahan data ini merupakan tahap akhir yang dilakukan. Pada tahap ini dilakukan perkalian antara bobot global setiap KPI dengan nilai Snorm setiap KPI sehingga didapatkan nilai akhir kinerja supply chain setiap KPI dan nilai total kinerja pabrik.

\section{Hasil dan Pembahasan}

\section{Gambaran Umum Perusahaan}

Pabrik Penggilingan Padi UD Sido Muncul merupakan salah satu pabrik penggilinga padi swasta yang terdapat di desa Labangka Barat, Kecamatan Babulu, Kabupaten Penajam Paser Utara.

Pabrik ini berdiri sejak tahun 2012 dengan rata-rata produksi beras mencapai 700 ton setiap tahun. Sumber bahan baku gabah yang didapatkan oleh pabrik ini berasal dari petani yang berada di wilayah Kecamatan Babulu dan juga petani yang berada di Banjar dan Batu Licin, Kalimantan Selatan. Pabrik ini menggunakan mesin penggilingan padi RMU Two Pass (husker Yanwar HW 602 unit, polisher N70 2 unit, motor penggerak Yanmar 6 HP dengan kapasitas input 1098 kg/jam). Pabrik ini melakukan penggilingan beras kemudian dipasarkan secara langsung kepada konsumen yang datang ke pabrik. Selain itu, pabrik ini juga memasarkan beras hasil produksinya kepada agen-agen beras baik yang berada di wilayah Kabupaten PPU seperti Penajam, Tanah Grogot, Long Kali maupun yang berada diluar wilayah Kabupaten PPU seperti Kota Balikpapan.

\section{Hasil Rancangan KPI}

Berdasarkan hasil wawancara dengan pemilik Pabrik sebagai pemilik yang berperan sebagai ahli terhadap bidang yang dibahas untuk merancang KPI pabrik penggilingan padi UD Sido Muncul, maka didapatkan hasil rancangan KPI sebanyak 27 KPI yang terbagi berdasarkan 13 variabel (level 2) dan 5 kriteria (level 1) yang dapat dilihat pada Tabel 3.

Tabel 3. Hasil rancangan KPI pabrik penggilingan padi UD Sido Muncul

\begin{tabular}{|c|c|c|c|c|}
\hline Level 1 & Level 2 & Level 3 & Kode & No \\
\hline \multirow{7}{*}{ Plan (P) } & \multirow{6}{*}{ Reliability (R) } & Akurasi target produksi beras $(\%)$ & PR-1 & 1 \\
\hline & & Akurasi anggaran biaya produksi beras (\%) & PR-2 & 2 \\
\hline & & Akurasi perkiraan penggunaan bahan bakar mesin (\%) & PR-3 & 3 \\
\hline & & $\begin{array}{l}\text { Akurasi anggaran biaya pengambilan gabah dari petani } \\
\text { luar daerah }(\%)\end{array}$ & PR-4 & 4 \\
\hline & & Persediaan kemasan beras & PR-5 & 5 \\
\hline & & Persediaan beras di gudang & PR-6 & 6 \\
\hline & Responsiveness $(\mathrm{Re})$ & Penyesuaian jadwal penggilingan padi & $\mathrm{PRe}$ & 7 \\
\hline \multirow{3}{*}{ Source (S) } & \multirow{3}{*}{ Reliability (R) } & Lead time waktu pemenuhan kemasan (\%) & SR-1 & 8 \\
\hline & & Ketepatan jumlah kemasan yang dipesan (\%) & SR-2 & 9 \\
\hline & & Kualitas gabah dari petani (\%) & SR-3 & 10 \\
\hline
\end{tabular}




\begin{tabular}{|c|c|c|c|c|}
\hline & & Kehandalan kinerja karyawan (\%) & SR-4 & 11 \\
\hline & Responsiveness $(\mathrm{Re})$ & Respon terhadap keluhan mengenai kemasan (\%) & SRe & 12 \\
\hline & Agility (Ag) & Ketersediaan pemasok kemasan (\%) & SAg & 13 \\
\hline \multirow{6}{*}{ Make (M) } & \multirow{3}{*}{ Reliability (R) } & Kesesuaian output dengan input (\%) & MR-1 & 14 \\
\hline & & Tingkat efisiensi mesin $(\%)$ & MR-2 & 15 \\
\hline & & Jumlah beras rusak & MR-3 & 16 \\
\hline & \multirow{2}{*}{ Responsiveness $(\mathrm{Re})$} & Ketepatan waktu produksi beras (\%) & MRe-1 & 17 \\
\hline & & Waktu set up mesin & $\mathrm{MRe}-2$ & 18 \\
\hline & $\operatorname{Cost}(\mathrm{C})$ & Kesesuaian biaya (Efisiensi Biaya) & $\mathrm{MC}$ & 19 \\
\hline \multirow{5}{*}{$\begin{array}{l}\text { Deliver } \\
\text { (D) }\end{array}$} & \multirow{3}{*}{ Reliability (R) } & Tingkat pemenuhan pesanan setiap pengiriman $(\%)$ & DR-1 & 20 \\
\hline & & Ketepatan jumlah beras yang dikirim (\%) & DR-2 & 21 \\
\hline & & Kualitas beras setelah proses pengiriman (\%) & DR-3 & 22 \\
\hline & Responsiveness (Re) & $\begin{array}{l}\text { Kecepatan tanggapan dalam memenuhi permintaan } \\
\text { pengiriman beras yang mendadak }\end{array}$ & $\mathrm{DRe}$ & 23 \\
\hline & Flexibility (F) & $\begin{array}{l}\text { Jumlah minimal pemesanan beras yang harus dipenuhi } \\
\text { dalam setiap pengiriman }\end{array}$ & $\mathrm{DF}$ & 24 \\
\hline \multirow{3}{*}{ Return (R) } & \multirow{2}{*}{ Reliability (R) } & Tingkat keluhan konsumen (\%) & RR-1 & 25 \\
\hline & & Jumlah penggantian beras & RR-2 & 26 \\
\hline & Responsiveness $(\mathrm{Re})$ & Jangka waktu menanggapi keluhan & $\mathrm{RRe}$ & 27 \\
\hline
\end{tabular}

Sumber: Hasil Pengolahan Data 2019

\section{Dashboard Hirarki}

Berdasarkan KPI yang sudah dirancang, maka dilakukan pembuatan hirarki sistem pengukuran kinerja sebagai dashboard bagi pemilik pabrik yang dapat dilihat pada Gambar 1 .

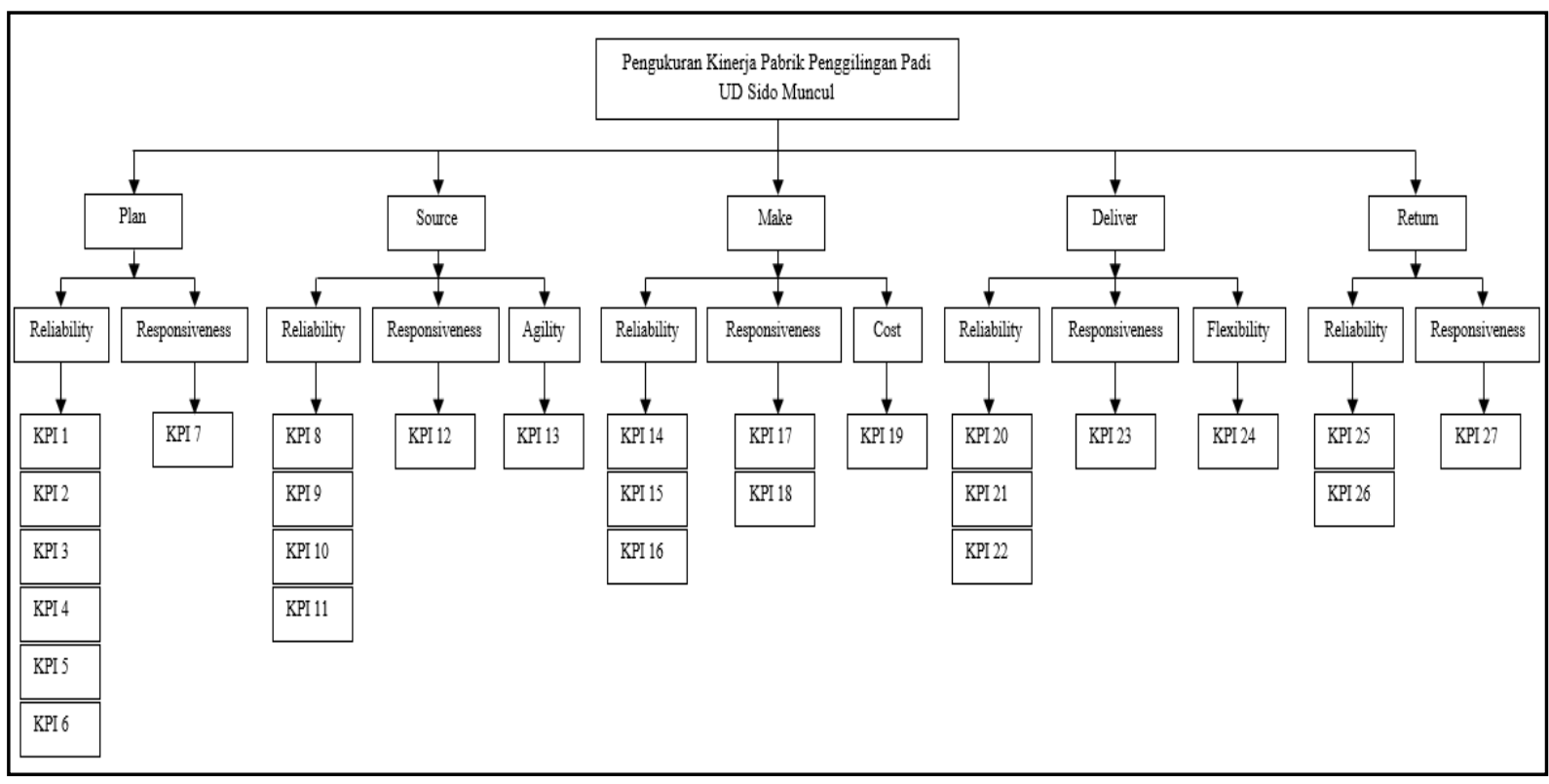

Gambar 1. Hirarki pengukuran kinerja pabrik penggilingan padi UD Sido Muncul

\section{Pembobotan Kriteria, Variabel, dan KPI}

Pembobotan dilakukan dengan melakukan perbandingan berpasangan menggunakan Software Expert Choice. Pertama kali dilakukan pembobotan antar kriteria, kemudian antar variabel disetiap masing-masing kriteria, selanjutnya pembobotan antar KPI, lalu pembobotan KPI disetiap krtiteria dan variabel. Setelah pembobotan selesai, dilakukan normalisasi untuk setiap hasil pembobotan.
Dari hasil pembobotan menggunakan metode AHP didapatkan bobot kriteria tertinggi yaitu plan sebesar 0,453 diikuti kriteria source sebesar 0,277, kriteria make sebesar 0,155, kriteria deliver sebesar 0,074, dan kriteria return sebesar 0,041 .

Bobot variabel reliability dan responsiveness pada kriteria plan sebesar 0,750 dan 0,250. Bobot variabel reliability, responsiveness, dan agility sebesar 0,637, 
0,258 , dan 0,105 . Bobot variabel reliability, responsiveneess, dan cost sebesar 0,637, 0,258, dan 0,105. Bobot variabel reliability, responsiveess, dan flexibility sebesar 0,637, 0,258 , dan 0,105 . Bobot variabel reliability dan responsiveness sebesar 0,750 dan 0,250. Bobot KPI 1 sampai dengan KPI 6 pada planreliability sebesar $0,213,0,302,0,185,0,127$, 0,090, dan 0,082. Bobot KPI 7 pada planresponsiveness adalah 1 karena tidak dilakukan perbandingan berpasangan. Bobot KPI 8 sampai dengan KPI 11 pada source-reliability sebesar 0,067, 0,067, 0,282, dan 0,583. Bobot KPI 12 pada source-responsiveness dan KPI 13 pada source-agility adalah 1 karena tidak dilakukan perbandingan berpasangan. Bobot KPI 14 sampai dengan 16 pada makereliability sebesar $0,127,0,223$, dan 0,651 . Bobot KPI 17 dan 18 pada makeresponsiveness sebesar 0,750 dan 0,250. Bobot KPI 19 pada make-cost adalah 1 karena tidak dilakukan perbandingan berpasangan. Bobot KPI 20 sampai dengan KPI 21 pada deliverreliability sebesar 0,127, 0,223, dan 0,651. Bobot KPI 23 pada deliver-responsiveness dan KPI 24 pada deliver-flexibility adalah 1 karena tidak dilakukan perbandingan berpasangan. Bobot KPI 25 dan 26 pada return-reliability sebesar 0,750 dan 0,250 dan bobot KPI 27 adalah 1 karena tidak dilakukan perbandingan berpasangan.

\section{Uji Konsistensi}

Setelah dilakukan perbandingan berpasangan dan pembobotan, maka dilakukan uji konsistensi untuk kriteria, variabel dan KPI yang dibobotkan berdasarkan perbandingan berpasangan. Hasil uji konsistensi kriteria adalah CR sebesar 0,097 dan dikatakan konsisten karena lebih kecil dari 0,1. Hasil uji konsistensi variabel pada kriteria plan adalah CI sebesar 0 dan dikatakan konsisten sesuai teori Saaty. Uji konsistensi variabel pada kriteria source adalah CR sebesar 0,048 dan dikatakan konsisten karena lebih kecil dari 01. Uji konsistensi variabel pada kriteria make adalah CR sebesar 0,048 dan dikatakan konsisten karena lebih kecil dari 0,1. Uji konsistensi variabel pada kriteria deliver adalah CR sebesar 0,048 dan dikatakan konsisten karena lebih kecil dari 0,1. Uji konsistensi variabel pada kriteria return adalah CI sebesar 0 dan dikatakan konsisten sesuai teori Saaty. Uji konsistensi KPI pada variabel plan-reliability adalah CR sebesar 0,099 dan dikatakan konsisten karena lebih kecil dari 0,1. Uji konsistensi KPI pada variabel sourcereliability adalah CR sebesar 0,048 dan dikatakan konsisten karena lebih kecil dari 0,1. Uji konsistensi KPI pada variabel makereliability adalah CR sebesar 0,048 dan dikatakan konsisten karena lebih kecil dari 0,1. Uji konsistensi KPI pada variabel makeresponsiveness adalah CI sebesar 0 dan dikatakan konsisten sesuai teori Saaty. Uji konsistensi KPI pada variabel deliverreliability adalah CR sebesar 0,048 dan dikatakan konsisten karena lebih kecil dari 0,1. Uji konsistensi KPI pada variabel returnreliability adalah $\mathrm{CI}$ sebesar 0 dan dikatakan konsisten sesuai teori Saaty.

\section{Penentuan Bobot Global}

Penentuan bobot global dilakukan untuk mendapatkan nilai akhir kinerja supply chain yang mana bobot global masing-masing KPI akan dikalikan dengan nilai aktual masing-masing KPI. Bobot global didapatkan dari hasil perkalian bobot setiap kriteria dengan bobot setiap variabel dan dengan bobot setiap KPI. Hasil perhitungan bobot global dapat dilihat pada Tabel 4.

Tabel 4. Bobot Global

\begin{tabular}{|c|c|c|c|c|c|c|}
\hline Kriteria & Bobot & Variabel & Bobot & KPI & Bobot & $\begin{array}{l}\text { Bobot } \\
\text { Global }\end{array}$ \\
\hline \multirow{7}{*}{ Plan (P) } & \multirow{7}{*}{0,453} & \multirow{6}{*}{ Reliability (R) } & \multirow{6}{*}{0,750} & 1 & 0,213 & 0,0724 \\
\hline & & & & 2 & 0,302 & 0,1026 \\
\hline & & & & 3 & 0,185 & 0,0629 \\
\hline & & & & 4 & 0,127 & 0,0431 \\
\hline & & & & 5 & 0,090 & 0,0306 \\
\hline & & & & 6 & 0,082 & 0,0279 \\
\hline & & Responsiveness $(\mathrm{Re})$ & 0,250 & 7 & 1,000 & 0,1133 \\
\hline Source $(\mathrm{S})$ & 0,277 & Reliability $(\mathrm{R})$ & 0,637 & 8 & 0,067 & 0,0118 \\
\hline
\end{tabular}

8 


\begin{tabular}{|c|c|c|c|c|c|c|}
\hline & & & & 9 & 0,067 & 0,0118 \\
\hline & & & & 10 & 0,282 & 0,0498 \\
\hline & & & & 11 & 0,583 & 0,1029 \\
\hline & & Responsiveness $(\mathrm{Re})$ & 0,258 & 12 & 1,000 & 0,0715 \\
\hline & & Agility $(\mathrm{Ag})$ & 0,105 & 13 & 1,000 & 0,0291 \\
\hline \multirow{6}{*}{ Make (M) } & \multirow{6}{*}{0,155} & \multirow{3}{*}{ Reliability (R) } & \multirow{3}{*}{0,637} & 14 & 0,127 & 0,0125 \\
\hline & & & & 15 & 0,223 & 0,0220 \\
\hline & & & & 16 & 0,651 & 0,0643 \\
\hline & & \multirow{2}{*}{ Responsiveness $(\mathrm{Re})$} & \multirow{2}{*}{0,258} & 17 & 0,750 & 0,0300 \\
\hline & & & & 18 & 0,250 & 0,0100 \\
\hline & & $\operatorname{Cost}(\mathrm{C})$ & 0,105 & 19 & 1,000 & 0,0163 \\
\hline \multirow{5}{*}{ Deliver (D) } & \multirow{5}{*}{0,074} & \multirow{3}{*}{ Reliability (R) } & \multirow{3}{*}{0,637} & 20 & 0,127 & 0,0060 \\
\hline & & & & 21 & 0,223 & 0,0105 \\
\hline & & & & 22 & 0,651 & 0,0307 \\
\hline & & Responsiveness $(\mathrm{Re})$ & 0,258 & 23 & 1,000 & 0,0191 \\
\hline & & Flexibility $(\mathrm{F})$ & 0,105 & 24 & 1,000 & 0,0078 \\
\hline \multirow{3}{*}{ Return $(\mathrm{R})$} & \multirow{3}{*}{0,041} & \multirow{2}{*}{ Reliability (R) } & \multirow{2}{*}{0,750} & 25 & 0,750 & 0,0231 \\
\hline & & & & 26 & 0,250 & 0,0077 \\
\hline & & Responsiveness $(\mathrm{Re})$ & 0,250 & 27 & 1,000 & 0,0103 \\
\hline
\end{tabular}

\section{Pengolahan Nilai Aktual}

Nilai aktual didapatkan dari hasil pengolahan kuesioner nilai pencapaian dan target masing-masing KPI selama bulan bulan November 2019, nilai pencapaian dan target terburuk pada bulan Juni 2019, serta nilai pencapaian dan target terbaik pada bulan Juli 2019 dengan menggunakan persamaan nilai aktual. Nilai aktual digunakan untuk mendapatkan nilai akhir kinerja supply chain setelah dilakukan uji normalisasi. Berikut ini merupakan tabel hasil perhitungan nilai aktual yang dapat dilihat pada Tabel 5.

Tabel 5. Nilai aktual

\begin{tabular}{|c|c|c|c|c|c|c|}
\hline Kriteria & Variabel & KPI & $\begin{array}{c}\text { Nilai Aktual } \\
\text { Terburuk } \\
\text { (Juni 2019) } \\
\end{array}$ & $\begin{array}{c}\text { Nilai Aktual } \\
\text { Terbaik } \\
\text { (Juli 2019) }\end{array}$ & $\begin{array}{c}\text { Nilai Aktual } \\
\text { November } \\
2019 \\
\end{array}$ & Kategori \\
\hline \multirow{7}{*}{ Plan $(\mathrm{P})$} & \multirow{6}{*}{ Reliability (R) } & 1 & 65,882 & 76,21 & 71,765 & Larger is Better \\
\hline & & 2 & 51,947 & 75,700 & 81,015 & Larger is Better \\
\hline & & 3 & 57,143 & 94,737 & 76,923 & Larger is Better \\
\hline & & 4 & 47,307 & 82,828 & 65,946 & Larger is Better \\
\hline & & 5 & 0,750 & 1,000 & 1,000 & Larger is Better \\
\hline & & 6 & 0,659 & 0,762 & 0,763 & Larger is Better \\
\hline & Responsiveness $(\mathrm{Re})$ & 7 & 0,740 & 0,837 & 0,833 & Larger is Better \\
\hline \multirow{6}{*}{ Source (S) } & \multirow{4}{*}{ Reliability (R) } & 8 & 150 & 50 & 100 & Smaller is Better \\
\hline & & 9 & 75 & 100 & 100 & Larger is Better \\
\hline & & 10 & 76,470 & 94 & 84,706 & Larger is Better \\
\hline & & 11 & 88,009 & 89,295 & 89,122 & Larger is Better \\
\hline & Responsiveness $(\mathrm{Re})$ & 12 & 0 & 100 & 100 & Larger is Better \\
\hline & Agility $(\mathrm{Ag})$ & 13 & 75 & 100 & 100 & Larger is Better \\
\hline \multirow{6}{*}{ Make (M) } & \multirow{3}{*}{ Reliability (R) } & 14 & 76,470 & 94,118 & 84,706 & Larger is Better \\
\hline & & 15 & 89 & 91 & 90 & Larger is Better \\
\hline & & 16 & 3,5 & 0,5 & 0,8 & Smaller is Better \\
\hline & \multirow{2}{*}{ Responsiveness $(\mathrm{Re})$} & 17 & 95,686 & 102,357 & 95,686 & Larger is Better \\
\hline & & 18 & 1,2 & 0,8 & 1 & Smaller is Better \\
\hline & $\operatorname{Cost}(\mathrm{C})$ & 19 & 1,268 & 1,007 & 1,021 & Larger is Better \\
\hline \multirow{5}{*}{ Deliver (D) } & \multirow{3}{*}{ Reliability (R) } & 20 & 93,333 & 100 & 100 & Larger is Better \\
\hline & & 21 & 86,667 & 100 & 100 & Larger is Better \\
\hline & & 22 & 86,667 & 100 & 93,333 & Larger is Better \\
\hline & Responsiveness $(\mathrm{Re})$ & 23 & 2 & 0,5 & 1 & Smaller is Better \\
\hline & Flexibility $(\mathrm{F})$ & 24 & 0,867 & 1 & 1 & Larger is Better \\
\hline
\end{tabular}




\begin{tabular}{|c|c|c|c|c|c|c|}
\hline \multirow{3}{*}{ Return (R) } & \multirow{2}{*}{ Reliability $(\mathrm{R})$} & 25 & 120 & 0 & 60 & Smaller is Better \\
\cline { 2 - 7 } & & 26 & 2 & 0 & 1 & Smaller is Better \\
\cline { 2 - 7 } & Responsiveness $(\mathrm{Re})$ & 27 & 2 & 0,5 & 1 & Smaller is Better \\
\hline
\end{tabular}

\section{Normalisasi Snorm De Boer}

Hasil nilai aktual memiliki range nilai yang berbeda-beda setiap KPInya. Range nilai yang berbeda tersebut harus dinormalisasi agar dapat ditarik analisa dari hasil pengolahan nilai aktual. Setelah dilakukan normalisasi, nilai tersebut dapat digunakan untuk menghitung nilai akhir kinerja supply chain dengan cara mengalikannya dengan bobot global. Hasil dari perhitungan nilai normalisasi menggunakan persamaan perhitungan nilai normalisasi dapat dilihat pada Tabel 6.

Tabel 6. Nilai normalisasi tiap KPI

\begin{tabular}{|c|c|c|c|c|}
\hline KPI & $\begin{array}{l}\text { Nilai Aktual } \\
\text { Terburuk } \\
\text { (Juni 2019) }\end{array}$ & $\begin{array}{c}\text { Nilai Aktual } \\
\text { Terbaik } \\
\text { (Juli 2019) }\end{array}$ & $\begin{array}{c}\text { Nilai Aktual } \\
\text { November } \\
2019 \\
\end{array}$ & $\begin{array}{c}\text { Nilai } \\
\text { Normalisasi }\end{array}$ \\
\hline 1 & 65,882 & 76,21 & 71,765 & 56,962 \\
\hline 2 & 51,947 & 75,700 & 81,015 & 122,377 \\
\hline 3 & 57,143 & 94,737 & 76,923 & 52,615 \\
\hline 4 & 47,307 & 82,828 & 65,946 & 52,472 \\
\hline 5 & 0,750 & 1,000 & 1,000 & 100 \\
\hline 6 & 0,659 & 0,762 & 0,763 & 100,396 \\
\hline 7 & 0,740 & 0,837 & 0,833 & 95,752 \\
\hline 8 & 150 & 50 & 100 & 50 \\
\hline 9 & 75 & 100 & 100 & 100 \\
\hline 10 & 76,470 & 94 & 84,706 & 46,668 \\
\hline 11 & 88,009 & 89,295 & 89,122 & 86,498 \\
\hline 12 & 0 & 100 & 100 & 100 \\
\hline 13 & 75 & 100 & 100 & 100 \\
\hline 14 & 76,470 & 94,118 & 84,706 & 46,668 \\
\hline 15 & 89 & 91 & 90 & 50 \\
\hline 16 & 3,5 & 0,5 & 0,8 & 10 \\
\hline 17 & 95,686 & 102,357 & 95,686 & 0 \\
\hline 18 & 1,2 & 0,8 & 1 & 50 \\
\hline 19 & 1,268 & 1,007 & 1,021 & 94,429 \\
\hline 20 & 93,333 & 100 & 100 & 100 \\
\hline 21 & 86,667 & 100 & 100 & 100 \\
\hline 22 & 86,667 & 100 & 93,333 & 50 \\
\hline 23 & 2 & 0,5 & 1 & 33 \\
\hline 24 & 0,867 & 1 & 1 & 100 \\
\hline 25 & 120 & 0 & 60 & 50 \\
\hline 26 & 2 & 0 & 1 & 50 \\
\hline 27 & 2 & 0,5 & 1 & 33,333 \\
\hline
\end{tabular}

\section{Traffic Light System}

Traffic Light System mengkategorikan setiap KPI dari hasil normalisasi Snorm De Boer ke dalam 3 warna yang masing-masing memiliki range nilai yang berbeda. Pengkategorian range nilai setiap warna diberikan langsung oleh pemilik pabrik dengan bantuan penjelasan dari penulis. Warna hijau melambangkan kinerja KPI sudah mencapai performa yang diharapkan dan sangat baik. Warna hijau berada pada nilai 80 ke atas. Warna kuning melambangkan kinerja KPI tergolong ke dalam performa cukup. Warna kuning berada pada range nilai 40 sampai dengan 79 . Warna merah melambangkan kinerja KPI tergolong ke dalam performa kurang baik atau buruk. Warna merah berada pada range nilai 0 samapi dengan 39. Pengkategorian setiap KPI dapat dilihat pada Tabel 7. 
Tabel 7. Nilai normalisasi setiap KPI

\begin{tabular}{|c|c|c|c|c|c|c|}
\hline Kriteria & Variabel & KPI & $\begin{array}{c}\text { Nilai Aktual } \\
\text { Terburuk } \\
\text { (Juni 2019) }\end{array}$ & $\begin{array}{c}\text { Nilai Aktual } \\
\text { Terbaik } \\
\text { (Juli 2019) }\end{array}$ & $\begin{array}{c}\text { Nilai Aktual } \\
\text { November } \\
2019\end{array}$ & Nilai Normalisasi \\
\hline \multirow{7}{*}{ Plan (P) } & \multirow{6}{*}{ Reliability (R) } & 1 & 65,882 & 76,21 & 71,765 & 56,962 \\
\hline & & 2 & 51,947 & 75,700 & 81,015 & 122,377 \\
\hline & & 3 & 57,143 & 94,737 & 76,923 & 52,615 \\
\hline & & 4 & 47,307 & 82,828 & 65,946 & 52,472 \\
\hline & & 5 & 0,750 & 1,000 & 1,000 & 100 \\
\hline & & 6 & 0,659 & 0,762 & 0,763 & 100,396 \\
\hline & Responsiveness $(\mathrm{Re})$ & 7 & 0,740 & 0,837 & 0,833 & 95,752 \\
\hline \multirow{6}{*}{ Source (S) } & \multirow{4}{*}{ Reliability (R) } & 8 & 150 & 50 & 100 & 50 \\
\hline & & 9 & 75 & 100 & 100 & 100 \\
\hline & & 10 & 76,470 & 94 & 84,706 & 46,668 \\
\hline & & 11 & 88,009 & 89,295 & 89,122 & 86,498 \\
\hline & Responsiveness $(\mathrm{Re})$ & 12 & 0 & 100 & 100 & 100 \\
\hline & Agility (Ag) & 13 & 75 & 100 & 100 & 100 \\
\hline \multirow{6}{*}{ Make (M) } & \multirow{3}{*}{ Reliability (R) } & 14 & 76,470 & 94,118 & 84,706 & 46,668 \\
\hline & & 15 & 89 & 91 & 90 & 50 \\
\hline & & 16 & 3,5 & 0,5 & 0,8 & 10 \\
\hline & \multirow{2}{*}{ Responsiveness $(\mathrm{Re})$} & 17 & 95,686 & 102,357 & 95,686 & 0 \\
\hline & & 18 & 1,2 & 0,8 & 1 & 50 \\
\hline & $\operatorname{Cost}(\mathrm{C})$ & 19 & 1,268 & 1,007 & 1,021 & 94,429 \\
\hline \multirow{5}{*}{$\begin{array}{l}\text { Deliver } \\
\text { (D) }\end{array}$} & \multirow{3}{*}{ Reliability (R) } & 20 & 93,333 & 100 & 100 & 100 \\
\hline & & 21 & 86,667 & 100 & 100 & 100 \\
\hline & & 22 & 86,667 & 100 & 93,333 & 50 \\
\hline & Responsiveness $(\mathrm{Re})$ & 23 & 2 & 0,5 & 1 & 33 \\
\hline & Flexibility $(\mathrm{F})$ & 24 & 0,867 & 1 & 1 & 100 \\
\hline \multirow{3}{*}{ Return (R) } & \multirow{2}{*}{ Reliability (R) } & 25 & 120 & 0 & 60 & 50 \\
\hline & & 26 & 2 & 0 & 1 & 50 \\
\hline & Responsiveness $(\mathrm{Re})$ & 27 & 2 & 0,5 & 1 & 33,333 \\
\hline
\end{tabular}

\section{Nilai Akhir Kinerja Supply Chain}

Nilai normalisasi untuk setiap nilai aktual KPI sudah didapatkan dengan menggunakan perhitungan normalisasi Snorm De Boer. Penentuan nilai kinerja supply chain pabrik pada bulan November dapat dihitung dengan cara mengalikan nilai normalisasi dengan bobot global. Hasil perhitungan tersebut dapat dilihat pada Tabel 8 .

Tabel 8. Nilai akhir kinerja supply chain pabrik penggilingan padi UD Sido Muncul

\begin{tabular}{|c|c|c|c|c|c|c|c|c|}
\hline Kriteria & Bobot & Variabel & Bobot & KPI & Bobot & $\begin{array}{l}\text { Bobot } \\
\text { Global }\end{array}$ & $\begin{array}{c}\text { Nilai } \\
\text { Normalisasi }\end{array}$ & $\begin{array}{l}\text { Nilai Akhir } \\
\text { Kinerja }\end{array}$ \\
\hline \multirow{7}{*}{ Plan (P) } & \multirow{7}{*}{0,453} & \multirow{6}{*}{ Reliability (R) } & \multirow{6}{*}{0,750} & 1 & 0,213 & 0,0724 & 56,962 & 4,122 \\
\hline & & & & 2 & 0,302 & 0,1026 & 122,377 & 12,556 \\
\hline & & & & 3 & 0,185 & 0,0629 & 52,615 & 3,307 \\
\hline & & & & 4 & 0,127 & 0,0431 & 52,472 & 2,264 \\
\hline & & & & 5 & 0,090 & 0,0306 & 100 & 3,058 \\
\hline & & & & 6 & 0,082 & 0,0279 & 100,396 & 2,797 \\
\hline & & Responsiveness $(\mathrm{Re})$ & 0,250 & 7 & 1,000 & 0,1133 & 95,752 & 10,844 \\
\hline \multirow{6}{*}{ Source (S) } & \multirow{6}{*}{0,277} & \multirow{4}{*}{ Reliability (R) } & \multirow{4}{*}{0,637} & 8 & 0,067 & 0,0118 & 50 & 0,591 \\
\hline & & & & 9 & 0,067 & 0,0118 & 100 & 1,182 \\
\hline & & & & 10 & 0,282 & 0,0498 & 46,668 & 2,322 \\
\hline & & & & 11 & 0,583 & 0,1029 & 86,498 & 8,898 \\
\hline & & Responsiveness $(\mathrm{Re})$ & 0,258 & 12 & 1,000 & 0,0715 & 100 & 7,147 \\
\hline & & Agility $(\mathrm{Ag})$ & 0,105 & 13 & 1,000 & 0,0291 & 100 & 2,909 \\
\hline \multirow[b]{2}{*}{ Make (M) } & \multirow[b]{2}{*}{0,155} & \multirow[b]{2}{*}{ Reliability $(\mathrm{R})$} & \multirow{2}{*}{0,637} & 14 & 0,127 & 0,0125 & 46,668 & 0,585 \\
\hline & & & & 15 & 0,223 & 0,0220 & 50 & 1,101 \\
\hline
\end{tabular}




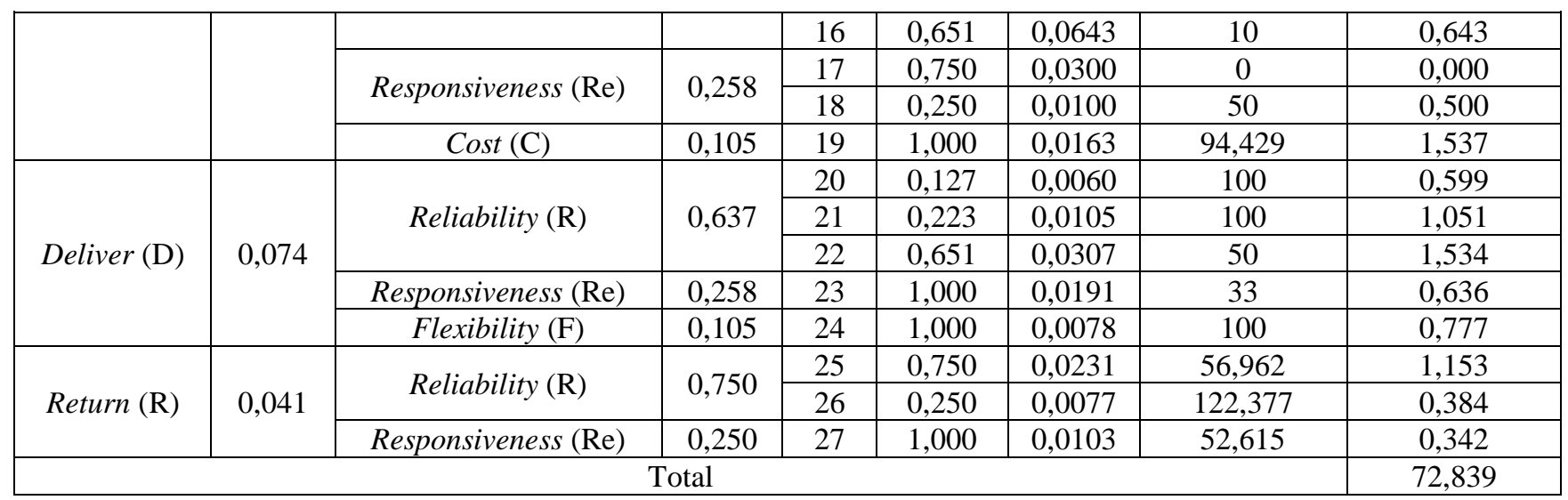

Berdasarkan tabel di atas, dapat diketahui bahwa total kinerja supply chain Pabrik Penggilingan Padi UD Sido Muncul adalah sebesar 72,839. Berdasarkan nilai tersebut maka dapat disimpulkan bahwa kinerja pabrik sudah mencapai Good Performance yang artinya sudah cukup baik. Kinerja pabrik masih dapat dioptimalkan lagi dengan cara meningkatkan kinerja KPI yang tergolong ke daam warna merah atau kinerja buruk sehingga dapat meningkatkan pendapatan pabrik.

\section{Kesimpulan dan Saran}

\section{Kesimpulan}

Berdasarkan hasil penelitian yang dilakukan pada Pabrik Penggilingan Padi UD Sido Muncul, maka dapat ditarik kesimpulan sebagai berikut:

1. Rancangan KPI berdasarkan model SCOR untuk sistem pengukuran kinerja supply chain Pabrik Penggilingan Padi UD Sido Muncul mendapatkan 27 KPI. Kriteria plan terdiri dari 7 KPI yaitu KPI 1 sampai dengan KPI 7. Kriteria Source terdiri dari 6 KPI yaitu KPI 8 sampai dengan KPI 13. Kriteria make terdiri dari 6 KPI yaitu KPI 14 sampai dengan KPI 19. Kriteria deliver terdiri dari 5 KPI yaitu KPI 20 sampai dengan KPI 24. Kriteria return terdiri dari 3 KPI yaitu KPI 25 sampai dengan KPI 27.

Hasil rancangan KPI juga didampingi dengan persamaan perhitungan nilai aktual untuk masing-masing KPI sehingga hasil rancangan KPI tersebut sudah dapat digunakan untuk pengukuran kinerja supply chain Pabrik Penggilingan Padi UD Sido Muncul.

2. Berdasarkan hasil pengkategorian KPI menggunakan Traffic Light System, diketahui bahwa terdapat 12 KPI yang berwarna hijau atau tergolong ke dalam kinerja yang sangat baik, 11 KPI yang berwarna kuning atau tergolong ke dalam kinerja cukup, dan 4 KPI yang berwarna merah atau tergolong ke dalam performa buruk.

3. Berdasarkan hasil perhitungan nilai kinerja akhir supply chain, maka diketahui total kinerja supply chain Pabrik Penggilingan Padi UD Sido Muncul adalah 72,839. Nilai tersebut tergolong ke dalam Good Performance yang artinya kinerja Pabrik Penggilingan Padi UD Sido Muncul sudah cukup baik. Berdasarkan hasil ini, meskipun kinerja keseluruhan supply chain sudah baik, kinerja pabrik masih perlu ditingkatkan lagi karena masih terdapat 4 kinerja KPI yang masih buruk. Apabila 4 kinerja KPI tersebut dapat ditingkatkan, maka akan mengoptimalkan kinerja supply chain Pabrik Penggilingan Padi UD Sido Muncul.

\section{Saran}

Berdasarkan hasil penelitian ini, diketahui bahwa total kinerja supply chain Pabrik Penggilingan Padi UD Sido Muncul berada pada kategori Good Performance. Kinerja supply chain pabrik terbilang cukup baik. Meskipun demikian, masih terdapat beberapa kinerja KPI yang tergolong ke dalam kinerja buruk sehingga perlu ditingkatkan lagi. Langkah pertama yang harus diambil adalah dengan meningkatkan kinerja buruk pada 4 KPI yang sudah teridentifikasi dari hasil Traffic Light System. Kemudian secara 
perlahan meningkatkan 11 kinerja KPI yang tergolong pada kategori cukup.

Saran untuk penelitian selanjutnya, sebaiknya melakukan penelitian pengukuran kinerja supply chain setidaknya 1 tahun atau 12 periode pencapaian kinerja. Hal ini dikarenakan agar terdapat kinerja pembanding setiap periode sebagai acuan pabrik untuk meningkatkan kinerja pabrik penggilingan padi pada periode selanjutnya.

\section{Daftar Pustaka}

[1] Agami, N., Saleh, M., Rasmy, M., 2012, Supply Chain Performance Measurement Approaches: Review and Classification, Jurnal of Organizational Management Studies, Vol. 2012, Hal. 20, IBIMA Publishing, Egypt.

[2] Apriyani, D., Nurmalina, R. \& Burhanuddin, 2018, Evaluasi Kinerja Rantai Pasok Sayuran Organik dengan Pendekatan Supply Chain Operation Reference (SCOR), Jurnal Ilmiah Manajemen, Vol. 8, No. 2, Hal 312-335, ISSN: 2088-1231.

[3] Azmiyati, S., Hidayat, S., 2016, Pengukuran Kinerja Rantai Pasok pada PT Louserindo Megah Permai Menggunakan Model SCOR dan FAHP, Jurnal Al-Azhar Indonesia Seri Sains dan Teknologi, Vol. 3, No. 4, Hal. 165.

[4] Badan Ketahanan Pangan, 2018, Laporan Tahunan Badan Ketahanan Pangan Tahun 2018, Badan Ketahanan Pangan Kementerian Pertanian, 45, Kementerian Pertanian, Jakarta Selatan.

[5] Badan Pusat Statistik, 2013, Direktori Perusahaan Industri Penggilingan Padi Tahun 2012 Provinsi Kalimantan Timur, Direktori Perusahaan Industri Penggilingan Padi Tahun 2012, 75, Badan Pusat Satistik, Jakarta.

[6] Budiwan, A., \& Syahrial, R., 2018, Pengukuran Kinerja Rantai Pasok dengan Pendekatan Supply Chain Operation Reference (SCOR) pada Kelompok Tani di Pacitan, Jurnal Ilmu Pertanian "AGRIKA", Vol. 12, No. 2, Hal. 155-156.

[7] Chotimah, R. R., Purwanggono, B., \& Susanty, A., 2017, Pengukuran Kinerja Rantai Pasok Menggunakan Metode SCOR dan AHP Pada Unit Pengantongan
Pupuk Urea PT. Dwimatama Multikarsa Semarang.

[8] Lestari, D., \& Rohmani, A., 2018, Rancang Bangun Production Performance Management Systems (PPMS) Menggunakan Metode Pureshare pada Penggilingan Padi UD Barokah Kabupaten Demak, Journal of Information System, Vol. 3, No. 2, Hal. 111-112.

[9] Liputra, D.T., Santoso, \& Susanto, N.A., 2018, Pengukuran Kinerja Rantai Pasok dengan Model Supply Chain Operations Reference (SCOR) dan Metode Perbandingan Berpasangan, Jurnal Rekayasa Sistem Industri, Vol. 7, No. 2, ISSN: 2339-1499.

[10] Lubis, P. I., \& Kusumanto, I., 2018, Penilaian Kinerja Karyawan Menggunakan Metode Key Performance Indicators (KPI) (Studi Kasus: Cv. Bunda Bakery Pekanbaru), Jurnal Sains, Teknologi dan Industri Vol. 15, No. 2, ISSN: 1693-2390.

[11] Nugrahani, D., \& Sualiantoro, H., 2015, Pengukuran dan Evaluasi Kinerja Supply Chain dengan Menggunakan Pendekatan Balanced Scorecard-Analytical Network Process (BSC-ANP) di PT Madubaru Yogyakarta, Jurnal Teknik Industri.

[12] Padillah, H., Chrisnanto, Y. H., \& Wahana, A., 2016, Model Supply Chain Operation Reference (SCOR) dan Analytic Hierarchy Process (AHP) untuk Sistem Pengukuran Kinerja Supply Chain Management, ISBN: 978-602-99334-5-1.

[13] Perdana, Y., R., 2014, Perbaikan Kinerja dengan Pendekatan Supply Chain Operation Reference (SCOR) dan Fuzzy Analytical Hierarchy Process (AHP), Seminar Nasional IENACO, ISSN: 23374349.

[14] Pujawan, N., \& Mahendrawathi, 2010, Supply Chain Management Edisi Kedua, Guna Widya, Surabaya.

[15] Sam, Z. A., \& Indah, P.N., 2016, Manajemen Agribisnis Padi. ISBN: 978-.

[16] Sari, I.R.M., Winandi, R., \& Tinaprilla, N., 2017, Kinerja Rantai Pasok Sayuran dan Penerapan Contract Farming Models, Jurnal Ilmiah Manajemen, Vol. VII, No. 3, Hal. 498-517.

[17] Saryatmo, M.A., \& Gunawan, A.S., 2014, 
Metode Omax Dan Prism Pt2. Vol. 18(ISSN: 1410-2331), 61-70.

[18] Sepang, G.Y.M., Mandei, J.R., \& Pakasi, C.B.D., 2017, Manajemen Rantai Pasok Beras di Kecamatan Kotamobagu Selatan, Kota Kotamobagu, AgriSosioEkonomi Unsrat, Vol. 13, No. 1A, Hal. 225-238, ISSN: 1907-4298.

[19] Siahaya, Willem, 2014, Sukses Supply Chain Management Akses Demand Chain Management, Penerbit In Media, Bogor.

[20] Wiyono, A., \& Isfanovi, H., 2016, Kajian Konsep Kebijakan Infrastruktur Strategis untuk Pengendali Banjir Jakarta (Studi Kasus Giant Sea Wall dan Multi Purpose Deep Tunnel). Jurnal Teknik Sipil, 23(1) 51-62.

[21] Penajamkab, 2019, Wujudkan Swasembada Beras, PPU Akan Bangun Pabrik Beras dilihat 24 September 2019 http://www.penajamkab.go.id/?p=504.

[22] Ppukab, 2019, Luas Tanam, Panen, dan Puso Padi Sawah dan Padi Ladang Menurut Kecamatan tahun 2018, dilihat 4 Februari 2020 , http://www.ppukab.bps.go.id/statisticable/ 2019/11/28/421/luas-tanam-panen-danpuso-padi-sawah-dan-ladang-menurutkecamatan-2018.html. 